\title{
Short-term effects of feeding rats with glucose syrup fractions and dextrose
}

\author{
By G. G. BIRCH AND I. J. ETHERIDGE \\ National College of Food Technology, University of Reading, \\ Weybridge, Surrey \\ AND L. F. GREEN \\ Beecham Research and Development Laboratories, Brentford, Middlesex \\ (Received 5 February $1972-$ Accepted 16 fune 1972)

\begin{abstract}
I. Young female Wistar rats were fed for $18 \mathrm{~d}$ on diets containing dextrose, 43 dextrose equivalent (DE) glucose syrup, fractions of $43 \mathrm{DE}$ glucose syrup of high and low molecular weight or sucrose.

2. All rats gained weight and showed no gross external abnormalities or significant dental caries scores.

3. The concentrations of cholesterol, triglycerides, free fatty acids and glucose were determined in samples of liver and serum. Generally, these values tended to increase with increasing molecular weight of dietary carbohydrate in the order dextrose, glucose syrup fraction of low molecular weight, and glucose syrup fraction of high molecular weight.

4. Rats given the high-molecular weight glucose syrup fraction were found to have caecums twice the normal size.
\end{abstract}

Glucose syrups (Birch, Green \& Coulson, I970) are now widely used by the food industry, about I 50000 tonnes/year being produced by the largest UK manufacturer. Although certain physiological effects of glucose syrup have been reported (Macdonald, I970; Grenby, I97I), no attempt has been made to relate these effects to chemical constitution, perhaps not surprisingly since glucose syrups contain a very large number of component sugars. Glucose syrups consist of a series of $1 ; 4-\alpha-D-$ linked oligosaccharides, all composed of glucose residues and possessing molecular weights between $\mathrm{I} 80$ and several millions. In addition there is a small proportion of $\mathrm{I}, 6-\alpha-\mathrm{D}$-linked gluco-oligosaccharides and a larger proportion of $\mathrm{I}, 4$ - and $\mathrm{r}, 6-\alpha-\mathrm{D}-$ linked gluco-oligosaccharides. The latter type preponderate in those fractions of glucose syrup which have a molecular weight above 4000 . Commercial manufacturing processes, depending on whether these are acid or enzymic or acid-enzymic (dual) processes and depending on the specificity and type of the enzymes used, may yield considerable differences of distribution of the component saccharides. Because we have already begun the chemical characterization of glucose syrup in this laboratory (Birch, I968; Kheiri \& Birch, I969; Birch \& Kheiri, 197I), we now report a preliminary experiment which relates the fractions and chemical character of glucose syrup to some physiological effects in rats. 
EXPERIMENTAL

\section{Fractionation of glucose syrup}

Glucose syrup and its fractions were characterized by dextrose equivalent (DE, i.e. reducing power calculated as dextrose and expressed on a dry-weight basis). DE was determined by the standard method (CIRF, 1963). Further characterization was carried out by descending paper chromatography on Whatman No. $x$ paper in the system $n$-propanol: ethyl acetate: water $(6: 1: 3)$. Intensities of spots (made visible by silver nitrate in acetone and sodium hydroxide in methanol) were obtained in a chromatogram scanner (Chromoscan Mk II : Joyce Lobel and Co. Ltd, Gateshead upon Tyne) and these were used to determine the concentration of oligosaccharides present (Kheiri, I970).

Glucose syrup was supplied as a $43 \mathrm{DE}$ acid-converted spray-dried powder from Corn Products Co. (UK) Ltd, Manchester. Two fractions were prepared from this powder by precipitating an aqueous solution $(500 \mathrm{~g} / 1)$ with industrial methylated spirit (British Drug Houses Ltd, Poole, Dorset) at a final concentration of $80 \%(\mathrm{w} / \mathrm{v})$ alcohol. The supernatant fraction was decanted from the precipitated gum and evaporated under reduced pressure at $40-45^{\circ}$. This portion constituted the low-molecular weight fraction (LMG) of the glucose syrup containing oligosaccharides only up to maltohexaose (see Table I) and had a DE of 59. The dextrin precipitate was contaminated with the same sugars as were present in the LMG fraction. It was freed of these by redissolving in the same volume of water as in the original glucose syrup solution and then precipitating with industrial methylated spirit $(80 \%$ final alcohol concentration) a further five times. This fraction then constituted the high-molecular weight fraction (HMG) of the glucose syrup. It contained only oligosaccharides above malto-octaose and had a DE of $\mathrm{I}_{3}$ (see Table I).

\section{Diets}

The sucrose diet (group $\mathrm{I}$, see Table 2 ) consisted of $(\mathrm{g} / \mathrm{kg})$ : sucrose 673 , casein $23 \mathrm{I}$, L-cystine 2, maize oil 47, Briggs salt mixture (supplied by Nutritional Biochemicals Corp., Cleveland, Ohio, USA) 47 , and vitamins and choline hydrochloride according to (USA) National Research Council (1962) recommendations. The remaining diets were similar except that the appropriate carbohydrate was added in place of sucrose.

\section{Rat feeding and examination}

Five female Wistar rats ( 5 weeks old) were placed into each of five cages, one cage for each diet (Table 2). All rats were supplied with diet and water $a d$ lib. and were left undisturbed except for weighing twice per week. After i $8 \mathrm{~d}$ the animals were anaesthetized and killed; the livers were removed, frozen in liquid nitrogen and weighed. Blood was removed from aortas; serum was formed and frozen. Serums and livers were kept frozen $\left(-2 I^{\circ}\right)$ until analysed. Teeth were removed from the carcasses and examined for dental caries. The abdominal viscera were examined in situ. 


\section{Analytical procedures}

A Technicon AutoAnalyzer (Technicon Instruments Co. Ltd, Basingstoke, Hants) was used for determination of lipids and serum glucose, but not phospholipids.

\section{Estimation of lipids}

Lipids were extracted from homogenized samples with chloroform-methanol $(2: \mathrm{I})$, the extracts being filtered and washed with phosphate buffer at $\mathrm{pH} 4.0$ (Carlson \& Wadström, 1958). They were then determined by the methods given below.

Cholesterol. Serum cholesterol was determined by a modification of method N24A, Technicon Instruments Co. Ltd (Fosbrooke \& Pringle, 1970). Polar lipids, chromogens and glucose were absorbed by mixing isopropanol extracts with Zeolite mixture (Noble \& Campbell, 1970, but containing double their quantities of copper and lime reagents). For liver cholesterol, $\mathrm{r} \cdot 0 \mathrm{ml}$ of the chloroform lipid extract (appropriately diluted) was mixed with $8.5 \mathrm{ml}$ isopropanol and $0.5 \mathrm{ml}$ water: this was then mixed with the Zeolite mixture as was done for the determination of serum cholesterol.

Triglycerides. Serum triglycerides were extracted and treated exactly as described for cholesterol, and were determined according to normal procedure (Noble \& Campbell, 1970 ).

\section{Phospholipids}

These were extracted in the same way as lipids and were determined by a conventional method; the purified chloroform extracts were previously evaporated under a stream of nitrogen, and the lipids were digested with perchloric acid (Zilversmit \& Davis, 1950). Inorganic phosphate was then determined in weighed samples of the digesta according to the method of Fiske \& SubbaRow (1925).

\section{Free fatty acids}

Liver free fatty acids were determined by the AutoAnalyzer method (Dalton \& Kowalski, 1967), using a modified copper reagent (Weenink, 1969).

\section{Serum glucose}

A standard (Boehringer Mannheim GmbH, Biochemical Dept, West Germany) glucose oxidase-peroxidase method was used.

\section{RESULTS AND DISCUSSION}

Table I shows the distribution of sugars in the $43 \mathrm{DE}$ glucose syrup and its fractions. The method of fractionation gave a clear separation around oligosaccharides containing seven glucose residues (degree of polymerization (DP) 7) but sugars of DP 7 were inevitably lost as a result of this fractionation procedure. It is therefore important to note that if the two fractions described in Table 1 were recombined they would not constitute 43 DE glucose syrup.

Table 2 gives the mean results for each group of rats and, with the exception of the 
Table 1. Carbohydrate composition of 43 dextrose equivalent $(D E)$ glucose syrup and its fractions

\begin{tabular}{|c|c|c|c|c|c|c|c|c|}
\hline \multirow[b]{2}{*}{ Carbohydrate } & \multirow[b]{2}{*}{$\mathrm{DE}$} & \multicolumn{7}{|c|}{ Saccharide in carbohydrate $(\mathrm{g} / \mathrm{kg})$} \\
\hline & & Mono- & Di- & Tri- & Tetra- & Penta- & Hexa- & $\begin{array}{c}\text { Hepta- and } \\
\text { higher }\end{array}$ \\
\hline Whole glucose syrup & 43 & Igo & 170 & 120 & 90 & 80 & 60 & 290 \\
\hline Low-mol. wt fraction & 59 & 370 & 270 & 180 & 90 & 60 & 30 & 0 \\
\hline High-mol. wt fraction & $I_{3}$ & 0 & 0 & $\circ$ & $\circ$ & 0 & 0 & 1000 \\
\hline
\end{tabular}

dextrose-fed group, all groups had a mean weight gain of at least $4 \mathrm{~g} / \mathrm{d}$. All rats appeared healthy and showed no gross external abnormalities.

If the sucrose and glucose syrup groups (groups I and 2, Table 2) are considered as controls, the remaining groups (groups 3, 4 and 5 , Table 2, that is the dextrose group, the LMG group, and the HMG group respectively) show the same ranking order for all the tissue changes listed other than the concentrations of serum triglycerides and cholesterol. The results were compared by means of Student's $t$ test and significant differences are set out in Table 2. Highest values for liver cholesterol and liver phospholipids were seen in the HMG group, which were significantly greater than values for liver cholesterol and liver phospholipids in the dextrose, LMG and glucose syrup groups. Serum triglycerides were also significantly greater in the HMG group than in the dextrose, LMG and glucose syrup groups. The lower serum cholesterol value for the HMG group is close to that of the LMG group; and the serum cholesterol values for the glucose syrup, LMG and HMG groups are significantly greater than those for the dextrose and sucrose groups. The ranking order which holds true for all other concentrations listed in Table 2 indicates that, as the molecular weight of the carbohydrate portion of the diet increases, the weight gain, liver weight, and concentrations of cholesterol, free fatty acids and serum glucose increase accordingly. The weight gain and liver weight of the HMG group were very similar to that of the sucrose-fed group. The serum glucose value was also similar in these two groups but the serum cholesterol values differed markedly, being significantly higher in the HMG group. Furthermore, the dextrose-fed group (group 3) had a very low liver weight compared with the sucrose-fed group (group I) but both groups had similar values for total free liver fatty acids. This indicates that, though the dextrose-fed group had smaller livers, these must have been much fattier in texture than those of the sucrosefed rats in group I. These results conflict with many earlier reports about the hyperlipidaemic effects of sucrose in male rats, baboons and humans (Allen \& Leahy, 1966; Al-Nagdy, Miller \& Yudkin, 1970; Coltart \& Macdonald, 1971; Macdonald, I970, 1971), but it may be significant that our experiment was carried out with young female rats of the Wistar strain. Al-Nagdy et al. ( 1970 ) have shown that female rats lay down more body fat when fed on starch for roo $d$ than when fed on sucrose, but serum cholesterol was similar on either diet: without added essential fatty acid, female rats had a higher content of serum cholesterol when fed on starch than when fed on sucrose. In baboons, oestrogen may increase the removal of triglyceride from 


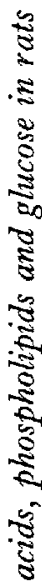

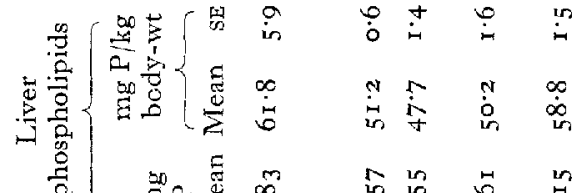

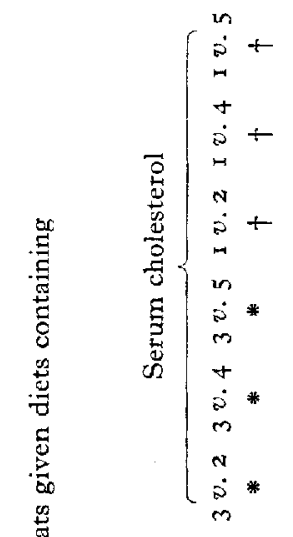

莺

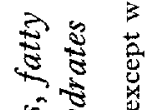

离空

홀

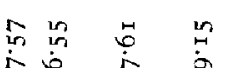

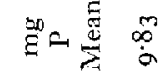

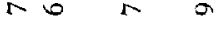

诺 管

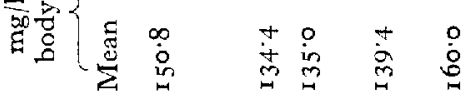

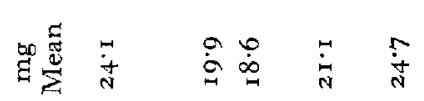

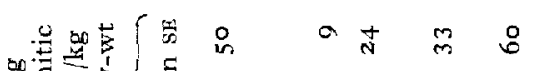

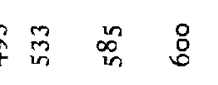

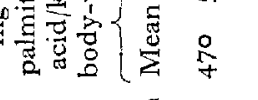

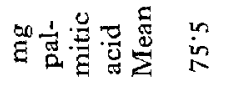

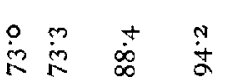

竞

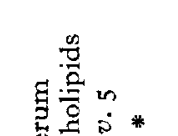

in $\stackrel{i}{i} \stackrel{\infty}{\dot{t}}$

苟

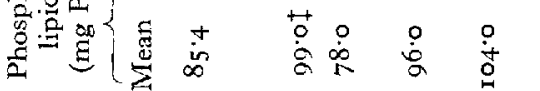

崖

in

है

D胥

昰

密

s.

के

(․․

亏ิ

苞

焉

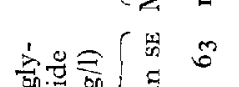

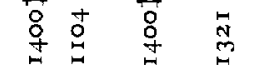

mi $m$ i

क्ष

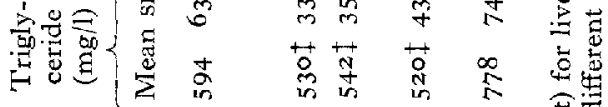

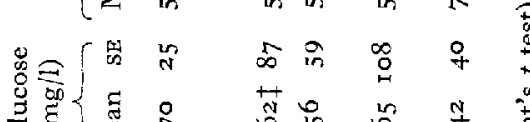

(

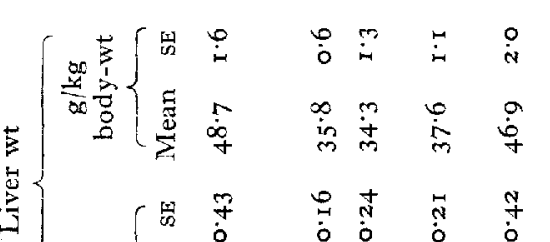

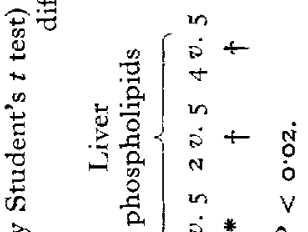

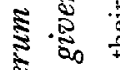

है

武

है

恣

密

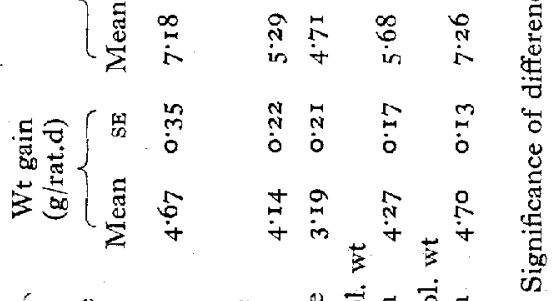

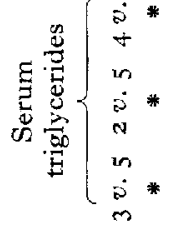


the serum of female animals (Coltart \& Macdonald, I97I). Thus female baboons fed on a high-sucrose diet do not suffer the same rise of serum triglycerides as do male baboons, but it is not clear whether these differences are due to the entire sucrose molecule or only to the fructose moiety. In humans the effects are evidently more distinct. Experiments show that, whereas diets containing fructose raise the fasting triglyceride concentration in men, the reverse effect seems to occur in young women (Antar \& Ohlson, 1965; Macdonald, I966).

The one gross abnormality that was noticeable in the HMG group (but no other group) was that of enlarged caccums (approximately twice normal size). All five rats in the group exhibited the same effect. Enlarged caecums have previously been observed by Chalvardjian \& Stephens (I970) in rats fed with dextrin; these may possibly be caused by the action of gut microflora. However, this hypothesis would imply poor absorption of at least a portion of the HMG fraction of the diet, whereas in fact none of the rats exhibited any flatulence or diarrhoea and all the faeces were well formed. Although the digestive system of the rat, like that of man, is well equipped with maltases, isomaltases and amylases, the enzymes may be of different types and possess different specificities and properties. Thus the human system contains intestinal as well as pancreatic amylases (Alpers \& Solin, r970) and, whereas the latter enzyme possesses an active site which binds five glucose residues of the polymer (Robyt \& French, I970), the former probably does not (Alpers \& Solin, I970). The different enzymes may act in concert for normal digestion and it is possible that intestinal amylase is of greatest importance during the rst year of infancy (Alpers \& Solin, r970) when maltodextrins of quite low molecular weight (e.g. maltohexaose) constitute part of the carbohydrate intake. It is by no means certain, however, that mixtures of enzymes which vary in their specificity can cope with the digestion of mixtures of differently processed carbohydrates. This in turn could be the explanation of earlier reports (Macdonald, 1970) that glucose syrups cause diarrhoea in most babies.

We were not able to measure the food intake of each group, and the results obtained may therefore be partly a result of dietary preferences. For instance, rats are sensitive to sweetness and prefer maltose to other sugars although it is less sweet than sucrose (Kare, 1970). However, in this experiment the greatest weight gain was in the HMG group where maltose was absent.

This $\mathrm{r} 8 \mathrm{~d}$ feeding trial resulted in no significant scores for dental caries in any of the rats and none of the results reported here, with the possible exception of the enlarged caecums, can be regarded as ill-effects. High-DE glucose syrups on the other hand may contain relatively high proportions of reversion products as well as other rare food sugars (Birch \& Kheiri, 1970) and, in view of the extreme toxicity of certain rare food sugars to humans (Birch, 197I), a longer feeding trial with highDE glucose syrup appears to be a logical continuation of this work.

This work was supported by a Science Research Council Co-operative Award in Pure Science in collaboration with Beecham Products (UK). We also wish to express our gratitude to Mr M. Ford (Beecham, Coleford), Dr Brenda Ryman and Miss 
Rosemary Irving (Royal Free Hospital School of Medicine). We are grateful to Professor Ian Macdonald (Guy's Hospital School of Medicine) for helpful discussions, and Corn Products Co. (UK) Ltd for samples of glucose syrup. We thank Mr N. D. Cowell for statistical advice and Dr T. H. Grenby (Guy's Hospital School of Medicine) for examination for dental caries.

\section{REFEREN CES}

Allen, R. J. L. \& Leahy, J. S. (I966). Br. F. Nutr. 20, 339.

Al-Nagdy, S., Miller, D. S. \& Yudkin, J. (1970). Nutr. Metab. 12, 193.

Alpers, D. H. \& Solin, M. (1970). Gastraenterology 58, 833 .

Antar, M. A. and Ohlson, M. A. (1965). F. Nutr. 85, 329.

Birch, G. G. (1968). \%. Fd Technol. 3, 159.

Birch, G. G. (1971). Lancet ii, I4rg.

Birch, G. G., Green, J. F. \& Coulson, C. B. (editors) (1970). Glucose Syrups and Related Carbohydrates p. Ir 8. Amsterdam, London and New York: Elsevier.

Birch, G. G. \& Kheiri, M. S. A. (1970). In Glucose Syrups and Related Carbohydrates p. 3 I [G. G. Birch, L. F. Green and C. B. Coulson, editors]. Amsterdam, London and New York: Elsevier.

Birch, G. G. \& Kheiri, M. S. A. (1971). Carbohydrate Res. 16, 215.

Carlson, L. A. \& Wadström, L. B. (1958). Scand. Y. clin. Lab. Invest. 10, 407.

Chalvardjian, A. \& Stephens, S. (1970). F. Nutr. Ioo, 397.

CIRF (1963). Standard Analytical Methods of the Member Companies of the Corn Industries Research Foundation p. E26. roor Connecticut Avenue, Washington 6, DC, USA: Corn Industries Research Foundation.

Coltart, T. M. \& Macdonald, I. (1971). Br. F. Nutr. 25, 323.

Dalton, C. \& Kowalski, C. (1967). Clin. Chem. 13, 744 .

Fiske, C. H. \& SubbaRow, Y. (1925). F. biol. Chem. 66, 375.

Fosbrooke, A. \& Pringle, G. A. (1970). Clinica chim. Acta 30, 47.

Grenby, T. H. (1971). Chem. Br. 7, 276.

Kare, M. (1970). Fd Wld 5, no. 5, p. I4.

Kheiri, M. S. A. (1970). An assessment of the composition of glucose syrups. PhD Thesis, University of Reading.

Kheiri, M. S. A. \& Birch, G. G. (I969). Cereal Chem. 46, 400.

Macdonald, I. (1966), Am. Y. clin. Nutr. 18, 369.

Macdonald, I. (r970). In Glucose Syrups and Related Carbohydrates p. 86. [G. G. Birch, L. F. Green and C. B. Coulson, editors]. Amsterdam, London and New York: Elsevier.

Macdonald, I. (I97I). In Sugar p. 192 [J. Yudkin, J. Edelman and L. Hough, editors]. London: Butterworths.

National Research Council (1962). Publs natn. Res. Coun., Wash. no. 990.

Noble, R. P. \& Campbell, F. M. (1970). Clin. Chemn. 16, 166.

Robyt, J. F. \& French, D. (1970). F. biol. Chem. 245, 3917.

Weenink, R. O. (1969). Clinica chim. Acta 24, I86.

Zilversmit, D. B. \& Davis, A. K. (1950). F. Lab. clin. Med. 35, I55. 